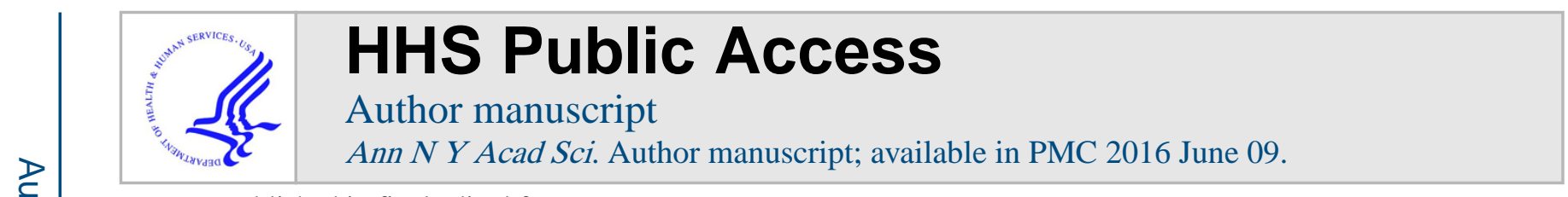

Published in final edited form as:

Ann N Y Acad Sci. 2010 January ; 1184: 208-224. doi:10.1111/j.1749-6632.2009.05113.x.

\title{
Epilepsy in the Elderly
}

\author{
Ilo E. Leppik, MDa and Angela K Birnbaum, $\mathrm{PhD}^{\mathrm{b}}$ \\ aProfessor of Pharmacy and Adjunct Professor of Neurology, University of Minnesota, and \\ Director of Research, MINCEP Epilepsy Care, Minneapolis \\ ${ }^{\mathrm{b}}$ Associate Professor of Pharmacy, Dept of Experimental and Clinical Pharmacology, University of \\ Minnesota
}

\begin{abstract}
The elderly, often defined as those 65 years or older, are the most rapidly growing segment of the population, and onset of epilepsy is higher in this age group than in any other. This paper reviews recent developments, including: a new proposed definition of epilepsy, a transgenic mouse model of Alzheimer's disease which exhibits complex partial seizures, evidence that the highest incidence of epilepsy may occur after admission to a nursing home, a challenge to the vitamin D hypothesis of osteoporosis associated with antiepileptic drugs (AEDs), evidence that the genetic complement of hepatic isoenzymes is more predictive of metabolic rate than age, and data showing that there is considerable variability in antiepileptic drug (AED) levels in many nursing home residents during constant dosing conditions.
\end{abstract}

\section{Keywords}

epilepsy; elderly; nursing homes; treatment

\section{Introduction}

The elderly, often defined as those 65 years or older, are the most rapidly growing segment of the US population. Demographic predictions indicate that their numbers will increase from an estimated 40 million in 2010 to 71.5 million in 2030. ${ }^{1}$ Epidemiologic studies have shown that the incidence of epilepsy is significantly higher in the elderly than in any age cohort. ${ }^{2}, 3$ During 1995 , for example, approximately 181,000 persons in the US developed epilepsy, 68,000 of whom were over the age of $65 .^{4}$ The incidence of epilepsy is high in the pediatric cohort, declines in younger adults, but begins to increase after age 55. Prevalence rates in community dwelling elderly in the US are approximately $1.5 \%$, considerably higher than the approximately $0.5 \%$ in younger adults. High rates of epilepsy in the elderly have also been reported from other developed countries. ${ }^{5}{ }^{6}$ In Finland, the number of elderly persons with epilepsy is now greater than those in the pediatric cohort, a reversal from just a few decades ago. Thus, due the projected increase in the number of elderly persons, as well

Correspondence: Ilo E. Leppik: 7500 Western Ave, Golden Valley, MN, 55427, Phone: 763-546-3328, Fax: 763-546-1013, leppi001@umn.edu. 
as their propensity to develop epilepsy, these individuals will represent an increasingly large group of patients needing expert care pertaining to this disorder.

\section{Definition of epilepsy and seizures}

At the present time, there is a debate within the epilepsy community regarding the precise definition of epilepsy ${ }^{7}$. Until recently, it has been accepted that persons should not be diagnosed with epilepsy until an individual experienced two or more seizures. The definition of two unprovoked seizures is used in epidemiologic studies, texts and often in practice.

However, with the diagnostic tools now available, specific central nervous disease processes can be readily identified. Epidemiologic studies have shown that persons with certain conditions, such as stroke or brain tumor, have a high probability of experiencing additional seizures after an initial ictal event. Often, there is also a desire to treat to prevent morbidity or mortality from further seizures. A committee of the International League Against Epilepsy (ILAE) has proposed that epilepsy be defined as a condition of the central nervous system (CNS) predisposed to seizure activity. ${ }^{8}$ The counter argument is that many persons with a CNS lesion may never have another seizure and diagnosing and treating everyone using the proposed definition may lead to over treatment and unnecessarily labeling many persons as having epilepsy. However, it is now necessary to use an ICD-9 code with every prescription. The code for epilepsy is 345.xx, but there is another code, 780.3, which is seizure not otherwise specified. Thus, if one wishes to treat after a single seizure but does not wish to diagnose a person as having epilepsy, the 780.3 may be used. This is of particular importance to the physician who wishes to decrease the risk of falls resulting in fractures or severe cardiac stress, but not use the epilepsy code. But treating after a single seizure will likely reduce the number of persons having a second seizure. Epidemiologic studies that use the two unprovoked seizure criteria may thus be compromised.

\section{Causes of Epilepsy}

The most common identifiable co-morbidity of epileptic seizures in the elderly is a previous stroke. Overall, from $30 \%$ to $40 \%$ of all epileptic seizure cases in the elderly are in persons who have had a stoke. ${ }^{2}$ In a prospective study of 1,897 patients suffering from stroke, seizures occurred in 168 (8.9\%) persons during a nine-month follow up period. ${ }^{9}$ Of the 265 persons within the study who suffered a hemorrhagic stroke, 28 (10.6\%) suffered a seizure; of 1,632 persons within the study who suffered an ischemic stoke, $140(8.6 \%)$ suffered a seizure. ${ }^{9}$ Thus, those who suffered a hemorrhagic stroke had a two-fold increased risk for a seizure as compared to those who suffered an ischemic stroke. During the nine months of follow-up in this study, epilepsy, as defined by the onset of a second seizure, occurred in 47 out of $1,897(2.5 \%)$ persons. A longer observation period might have detected a higher rate. Some retrospective studies have indicated that the eventual risk of experiencing seizures after suffering a stroke may be as high as $20 \%{ }^{10}$. It has been estimated that each year more than 730,000 persons in the US have a stroke. Projecting these data, the incidence of new seizures after stroke may exceed 36,000 cases per year. ${ }^{10}$

One confusing factor is that a transient ischemic attack (TIA) will sometimes lead to simple partial seizures whose pattern is similar to the deficit of the TIA. This may create a 
diagnostic dilemma and concern that another TIA is occurring. The major clinical differential feature between a TIA and a simple partial seizure is that of the length of the event. Simple partial seizures rarely last more than a few minutes whereas TIAs last much longer, usually hours.

Brain tumor, head injury, and Alzheimer's disease are other major causes of epilepsy in the elderly. It is suspected that those persons with Alzheimer's disease who experience brief periods of increased confusion may be having unrecognized partial complex seizures. ${ }^{11}$ Although the probable co-morbid condition and presumed cause can be identified in many cases, in approximately half of the cases the precise cause cannot be determined and the etiology is termed cryptogenic (crypt=hidden; genic=cause).

\section{Neurobiology of Aging and Epilepsy}

Although rodent models have a long history of contributing to the understanding of epilepsy, they have not been utilized to study issues of the aging brain and epilepsy. There are many reasons for this, but perhaps the most salient are the issues of obtaining appropriate aged animals. ${ }^{12}$ The National Institute on Aging (NIA) has an aged rodent colony of a limited number of strains. They also maintain a tissue bank from aged rodent colonies and have a number of human cell lines which includes samples from patients with convulsive disorders. However, the genetic background of animals is crucial because there are major species differences in susceptibility to seizures. ${ }^{12}$ For example, the C57BL/6 mice are completely resistant to audiogenic seizures whereas DBA/2 mice have a very low threshold to this type of stimulus. ${ }^{13}$ There are also major strain differences in susceptibility to maximal electroshock seizures (MES). To study the effects of aging on epilepsy, one would need to select an appropriate genetic strain and raise them through the life cycle to an elderly age. The cost of this would be considerable, and one would need a long grant (WOULD YOU RATHER SAY "a longer grant cycle than currently available") cycle to accomplish this.

One difficulty in studying the effect of aging on epilepsy is the heterogeneity of this disorder. The mechanism of developing epilepsy after a stroke may differ significantly form the process by which persons with Alzheimer's disease become susceptible to seizures. Even within the stroke category, hemorrhagic strokes may have a different mechanism than ischemic stroke. Then there are the large number of persons who have cryptogenic epilepsy. Nevertheless, there are a number of changes in the aging brain which may alter the seizure threshold.

In aging rodents, significant synaptic loss in the middle and inner molecular layers of the dentate gyrus has been demonstrated. ${ }^{14}$ Changes in the volume of human hippocampi can also be seen in humans using MRI scans. ${ }^{15}$ However, the effect of these processes on epileptogenisis is not easily understood. Long-term potentiation (LTP) is the long lasting augmentation of synaptic responses after brief trains of high frequency stimulation of monosynaptic pathways. There appears to be no significant difference in the extent of LTP between young and old animals in the Shaffer collateral-CA1 synapse and the perforant path-granular cell synapse. ${ }^{16}$ This may be due to the finding that NMDA receptor-dependent LTP is markedly reduced in aged animals while voltage-dependent calcium channel dependent LTP is significantly increased. ${ }^{17}$ Thus, the overall result of these two components 
of LTP may not show a change as a function of "normal" aging. However, in old memory impaired rats LTP declines much faster than in younger rats. Kindling was initially used as a model to study learning. Thus it is interesting to note that the process of kindling to spontaneous epilepsy is retarded in aged animals. ${ }^{18}$ This set of studies found a striking relationship between rate of kindling and memory; old rodents with poor memory kindled slowly whereas old rodents with good memory kindled rapidly. ${ }^{18}$ A human study of secondary epileptogenisis reported that older persons were much less likely to develop an independent secondary focus than younger ones. ${ }^{19}$ These studies suggest that the increased incidence of seizures in elderly patients may be due more to the frequency of various insults to the brain rather than an increase in susceptibility to epileptogenisis.

Because stroke (hemorrhagic and ischemic) is the major cause of symptomatic epilepsy in the elderly, study of animal models in this field may lead to important insights into developing strategies for the prevention of epilepsy after a stroke. Middle cerebral artery occlusion (MCAO) and photothrombosis with concomitant EEG recoding have been the most widely used models of ischemic infarction. In one study MCAO resulted in multiple generalized or focal ictal discharges within two hours of the insult, but clinical seizures were not observed. ${ }^{20}$ Another study of MCAO however found no evidence for clinical or EEG seizures in animals followed for one year. ${ }^{21}$ On the other hand, large photothrombotic infarctions are associated with electroencephalographic seizures. Another model uses glutamate excitotoxicity injury-induced epileptogenisis in hippocampal neuronal cultures. This has led to the $\mathrm{Ca}^{2+}$ hypothesis of epileptogenisis. ${ }^{22}$ It is hoped that a better understanding of the mechanisms of the development of epilptogenosis may eventually lead to therapeutic interventions. Recently a transgenic mouse model of Alzheimer's disease was found to have spontaneous nonconvulsive seizures accompanied by electroencephalographic changes reminiscent of human temporal lobe epilepsy. ${ }^{23}$

\section{Diagnosis}

The diagnosis of epilepsy is difficult in the elderly for many reasons. A good history may be difficult to obtain, many seizures may be subtle complex partial events, and seizures may be provoked. In the VA study \#428 of new onset epilepsy in a community dwelling cohort, many subjects eventually diagnosed as having epilepsy had been initially misdiagnosed. ${ }^{24}$ Because most seizures in the elderly are caused by a focal area of damage to the brain, the most common seizure types are localization related. Complex partial seizures are the most common seizure type, accounting for nearly $40 \%$ of all seizures in the elderly population. ${ }^{25}$ Both simple and complex seizures may spread and develop into generalized tonic-clonic seizures.

When considering the diagnosis of epilepsy, a clear distinction must be made between epileptic seizures - those arising from brain pathology - and non-epileptic seizures (provoked seizures) - those arising within a normal brain due to an alteration in physiology, such as hypoxia. It is imperative that provoked seizures be ruled out before concluding that the seizure was epileptic. Other causes of seizure activity, such as cardiac insufficiency, metabolic conditions, convulsive syncope (micturation syncope, cough syncope), must be eliminated as the etiological factors because a misdiagnosis can have serious consequences. 
Evaluation after a single seizure must therefore be comprehensive. A thorough history must be obtained, focusing on events of the previous day or days, in order identify any precipitating or predisposing factors that may have led to the onset. An EKG should be utilized in order to rule out possible cardiac conditions. Laboratory tests for metabolic disorders should be done, as well as a review of prescription drugs, over the counter agents, and natural products being used by the patient. Unfortunately, many natural products designed to simulate weight loss or improve memory may have pro-convulsant properties. Further, withdrawal from CNS depressants such as benzodiazepines or alcohol may provoke seizures. Stimulants such as methamphetamine and cocaine may cause convulsions. Unfortunately, abuse of drugs is not absent in the elderly and a drug screen should be considered.

\section{CT and MRI}

The use of cortical imaging studies is highly predictive of seizures. ${ }^{26}$ Structural studies, such as CT that screen for intracerebral hemorrhage, brain tumor, and encephalomalacia, should be performed following a convulsion. CT scans serve as an appropriate imaging tool for the initial emergency study. Because of its X-ray modality, it is capable of detecting tissue contrasts; therefore, it is effective in locating blood, areas of encephalomalacia, and calcified lesions. The CT scan is unable to appropriately visualize subtle changes in tissue density. Glial tumors, subtle changes within the hippocampus and other significant lesions may not be well visualized by a CT scan. Detection of these lesions require MRI, which is more appropriate for identifying subtle changes in brain tissue. An MRI should be requested if an obvious pathology is not detected by the initial CT scan.

\section{Electroencephalogram}

Electroencephalograms (EEG) serve many useful roles in the diagnosis of epilepsy.

Detection of interictal patterns can confirm the presence of physiologically abnormal brain, solidifying the diagnosis of an epileptic as opposed to a non-epileptic seizure. Additionally, interictal patterns can provide information on the severity of the epilepsy. Frequent interictal activity would suggest a more aggressive epileptogenic process and solidify the impetus for treatment. The presence of interictal activity on EEGs can also identify the epileptogenic region, providing additional clues to the etiology of the patient's disorder. Persons who experience periodic lateralized epileptiform discharges (PLEDs) after a stroke are also prone to develop epileptic seizures. ${ }^{27}$ Those with focal spikes have a $78 \%$ risk of developing epileptic seizures. ${ }^{28}$ It is recommended that an EKG rhythm strip be obtained during an EEG in order to help identify artifacts and to provide additional evidence to exclude a cardiac cause for the seizure.

\section{Complex issues}

Problems faced by the elderly suffering from epilepsy are different and more complex than those faced by younger adults also suffering from the same disorder. These problems involve medical complexities - e.g., correct diagnoses, selection of the most appropriate 
medication(s), and presence of co-morbid illnesses - as well other societal factors such as emotional stability and economic responsibilities.

\section{Falls, Fractures and Bone Health}

The presence of epilepsy increases the risk for falls and fractures by 2-6 fold. Osteoporosis and bone fractures are commonly seen in the elderly population and thus an elderly person with epilepsy is at increased risk. Lack of exercise, inadequate nutrition, impairment of mobility and neurological conditions leading to poor balance and protective reflexes may all play a role. Large prospective studies in women and men have associated use of both phenytoin and gabapentin with decreased bone mineral density. ${ }^{29}, 30$ The fact that nonenzyme inducing AEDS such as gabapentin and valproate both affect bone mineral density while carbamazepine, a strong inducer, does not, brings into question the commonly held belief that the AEDs influence on bone health is only through vitamin D metabolism. However, vitamin D supplementation is recommended for all elderly, with or without epilepsy. Not well studied is the possible influence of AED toxicity (ataxia, neuropathy, nystagmus, sedation) on falls. Because the elderly are more sensitive to AED side effects, care should be taken to avoid AED concentrations in the higher range effective for younger adults and levels below the usually effective range may be appropriate.

\section{Elderly are not a homogenous population}

The elderly are not a single cohort. Thus, broad statements about these persons may not be relevant to each individual patient. Just as medical issues involving persons up to 18 years of age cannot be properly interpreted without using newborn, infant, child, and adolescent subcategories, elderly persons should also be subdivided into appropriate cohorts. One system divides this group into the young-old (65-74 years of age); the middle-old or old (75-84 years of age); and the old-old ( $\geq 85$ years of age). However, because the elderly develop health issues at different ages, further subdivisions, such as the elderly healthy who have epilepsy $(E H)$, the elderly with multiple medical problems (EMMP), and the frail elderly, those usually found residing in nursing homes (NHs) $(F E)$, have also been proposed (Table 1). ${ }^{31}$

Adding to the complexity are the major differences between the community-dwelling elderly, those living independently, and the elderly residing within NHs. Drug side effects, efficacy, absorption, and other factors may be markedly different between a 93-year-old healthy person living independently and a 68 -year-old frail person residing in a $\mathrm{NH}$. In addition, issues regarding health care delivery will differ between the community-dwelling elderly and those residing within a NH. Thus, studies should be designed to address specific populations, and reports should specify the populations studied. ${ }^{32}$

Also seen as significantly problematic is the selection of an appropriate AED, which requires the consideration of many factors. Such factors include: changes in organ function, increased susceptibility to adverse effects, use of other medications known to interact with AEDs, and economic limitations associated with the respective patient. Further, pharmaceutical treatment within the elderly carries greater risks than in younger persons. In 
addition to their use in epilepsy, AEDs are prescribed for a variety of other disorders affecting the elderly, including pain and psychiatric disorders. AEDs rank fifth among all drug categories in their capacity to illicit adverse reactions. ${ }^{33}$ Yet, very little research has been done within this vulnerable population and only general recommendations can be made at this time.

\section{Pharmacoepidemiology of AED use in community-dwelling elderly}

The largest study of AED use in US community-dwelling elderly was coordinated by Berlowitz. ${ }^{34}, 35$ This study's cohort identified 1,130,155 veterans $\ 65$ years of age from the Veteran Administration's (VA) national database between 1997 and 1999. Of these persons, $20,558(1.8 \%)$ were identified as having epilepsy by exhibiting an ICD-9-CM diagnostic code representative of this condition. Approximately $80 \%$ of the studied persons were receiving one AED, whereas $20 \%$ were being treated with two or more. Phenytoin was used as monotherapy by almost $70 \%$ of the cohort, whereas phenobarbital was used as monotherapy by approximately $10 \%$. Another $5 \%$ were using phenobarbital in combination with phenytoin. Carbamazepine was used by just more than $10 \%$ and newer AEDs (gabapentin and lamotrigine) were used by less than $10 \% .{ }^{35}$ Levetiracetam was not available at the time of this survey. Smaller studies of AED use in community-dwelling non-VA elderly patients have shown similar distributions of AED use, with phenytoin by far being the most widely used AED in the US by this population. These studies done almost a decade ago from this writing and may not reflect current practice.

\section{Pharmacoepidemiology of AED use in nursing homes}

As people age, their need for $\mathrm{NH}$ care increases due to greater frailty and the likely onset of age-related diseases. For patients $\ 65$ years of age, there is a lifetime risk of $43 \%$ to $46 \%$ of becoming a NH resident. ${ }^{36}$ Accordingly, at any one time $4.5 \%$ of the US elderly population resides within a $\mathrm{NH}^{37}$ In epidemiological research concerning NHs, it is necessary to make distinctions between residents and admissions. A resident cohort includes all residents in the facility at a specified time, and usually represents a cross-sectional sample that consists of a mixture of newly admitted residents and those who have been in the NH for different periods of time. In contrast, an admissiosn cohort includes all people admitted to a facility during a specified time period. ${ }^{38}$

In a study of US NH residents residing within various facilities during the spring of 1995 the mean age of the 21,551 persons studied was 83.78 years ( $\mathrm{SD}=8.13$ years). ${ }^{38}$ The sample had the following age group distribution: young-old 15\%, middle-old or old $36 \%$, and old-old $49 \%$. This distribution is similar to the data provided by the US Census Bureau which, in 2000 described the admittance of $1,555,800$ persons to $\mathrm{NH}$ facilities. ${ }^{37}$ Of the residents in the Garrard et. al., NH sample, $10.5 \%$ had one or more AED orders on the day of study and $9.2 \%$ had a seizure indication (epilepsy or seizure disorder) documented in their computerized medical record. Phenytoin was used by $6.2 \%$ of the residents, followed by carbamazepine (1.8\%), phenobarbital (1.7\%), clonazepam (1.2\%), valproic acid (0.9\%), and all other AEDs combined (1.2\%). These percentages exceed $10.5 \%$ due to AED polytherapy. If these results are extrapolated to all 1,557,800 US elderly NH residents in 2000 then as 
many as 163,569 people were likely to have been receiving at least one AED. ${ }^{37}$ In the Garrard et. al., study, age was inversely related to AED use. Of the young-old cohort, 23.7\% were prescribed an AED - $16.4 \%$ for seizure indication, and $7.3 \%$ for other. Of the middleold or old, $12.2 \%$ were prescribed an AED - 8.3\% for seizure indication, and $3.9 \%$ for nonseizure indication. However, of the old-old cohort only $5.8 \%$ were prescribed an AED $3.7 \%$ for seizure indication, and $2.1 \%$ for other. Notably, this finding was unexpected because studies of community dwelling elderly show that the incidence of epilepsy/seizure disorder rises with advancing age. Thus, one of the major findings concerning AED use in US NHs is that the young-old are three to four times more likely to be prescribed an AED than the old-old, either prior to, or after admission. A similar pattern was reported from a study in Italy. ${ }^{39}$ The reason for this inverse relationship between community dwelling elderly and nursing home residents is unknown and needs to be further investigated. One hypothesis is that younger NH residents have a higher prevalence of the disorders predisposing to them epilepsy than older residents.

In a study of $\mathrm{NH}$ admissions using a longitudinal design to explore AED use at the time of admission, two study groups were used; the first representing all persons aged $\searrow 65$ years of age admitted between January 1 and March 31, 1999 to one of the 510 Beverly Enterprises NH facilities in 31 US states $(\mathrm{N}=10,318)$; while the second represented a follow-up cohort ( $n=9516)$ of those in the admissions group who were not using an AED at the time of NH admission. ${ }^{38}$ The cohort not receiving AEDs at the time of admission was followed for 3 months or until NH discharge - whichever occurred first - after their initial admission date. Approximately $8 \%(\mathrm{n}=802)$ of the admissions group used one or more AEDs at entry, and among these, greater than half $(58 \%)$ had an epilepsy/seizure disorder indication. The AEDs used by newly admitted individuals with an epilepsy/seizure disorder $(n=585)$ included phenytoin $(n=315 ; 54 \%)$, valproic acid $(n=57 ; 10 \%)$, carbamazepine $(n=52 ; 9 \%)$, and gabapentin $(\mathrm{n}=27 ; 5 \%)$.

Among the 9,516 residents within the follow-up cohort of the Garrard study who were not using an AED at admission, $260(3 \%)$ were started on an AED within 3 months of admission. Factors associated with the initiation of AEDs during this period included epilepsy/seizure, manic depression (bipolar disease), age group, cognitive performance (MDS-COGS), and peripheral vascular disease (PVD). Thus, many persons admitted without a diagnosis of epilepsy were given this diagnosis after entry to the NH. Based on this study, it seems that the incidence of newly diagnosed epilepsy after admission to the NH far exceeds numbers relevant to other age group populations. A crude estimate would be $600 / 100,000$ per 3 months, or four to six times that reported for community-dwelling elderly. AEDs used by those in the cohort which had AEDs started after admission and who had an epilepsy/seizure indication were: phenytoin 48\%, gabapentin 13\%, carbamazepine $12 \%$, valproic acid $8 \%$, phenobarbital $7 \%$, and other $12 \%$. There was also an inverse relationship between age group and initiation of an AED. Compared to the young-old, those in the middle-old or old age group were $33 \%$ less likely to have been prescribed an AED $(\mathrm{p}<0.05)$, whereas the old-old were $50 \%$ less likely to have been prescribed an AED. 38 
Another issue is that many elderly persons are taking other drugs (Table 2). In addition to AEDs, the average elderly $\mathrm{NH}$ patient takes six medications concomitantly, greatly increasing the risk for side effects and drug-drug interactions. ${ }^{40}$

\section{Clinical pharmacology of AEDs in the elderly}

The theoretical basis for expecting age related changes in drug pharmacokinetics were described many years ago, but have not been widely applied to AEDs. Drug concentration at the site of action determines the magnitude of both desired and toxic responses. The unbound drug concentration in serum is in direct equilibrium with the concentration at the site of action and provides the best correlation to drug response. ${ }^{41}$ Total serum drug concentration is useful for monitoring therapy when the drug is not highly protein bound (less than 75\%), or when the ratio of unbound to total drug concentration remains relatively stable. Three of the major AEDs (valproic acid, phenytoin, and carbamazepine, respectively) are highly bound, and their protein binding may be altered in the elderly. Age-related physiologic changes that appear to have the greatest effect on AED pharmacokinetics involve protein binding and a reduction in liver volume and blood flow. ${ }^{42 \_44}$ Reduced serum albumin and increased a1-acid glycoprotein (AAG) concentrations in the elderly alter protein binding of some drugs. ${ }^{41}{ }^{43}$ By age 65 , many individuals have low normal albumin concentrations or are considered hypoalbuminemic. Albumin concentration may be further reduced by conditions such as malnutrition, renal insufficiency, and rheumatoid arthritis. The concentration of AAG, a reactant serum protein, increases with age, and further elevations occur during pathophysiologic stress, such as stroke, heart failure, trauma, infection, myocardial infarction, surgery, and chronic obstructive pulmonary disease. ${ }^{43}$

Administration of enzyme-inducing AEDs also increases AAG. ${ }^{45}$ When the concentration of AAG rises, the binding of weakly alkaline and neutral drugs such as carbamazepine to AAG can increase, causing higher total serum drug concentrations and decreased unbound drug concentrations. Because of the complexity of confounding variables and the lack of correlation between simple measures of liver function and drug metabolism, the effect of age on hepatic drug metabolism remains largely unknown. ${ }^{46}, 47$ Interestingly, genetic determinants of hepatic isoenzymes may be more important than age in determining a person's clearance. ${ }^{48}$

Renal clearance is the major route of elimination for a number of newer AEDs. It is well known that an elderly person's renal capacity decreases by approximately $10 \%$ per decade. ${ }^{49}$ However, there exists a substantial amount of individual variability because clearance is also highly dependent upon the patient's general state of health. ${ }^{50}$ Thus, purely age-based dose recommendations may not be appropriate and measurements of serum creatinine and estimations of creatinine clearance may be more accurate.

Despite the theoretical effects of age-related physiologic changes on drug disposition and the widespread use of AEDs in the elderly, few studies on AED pharmacokinetics in the elderly have been published. The available reports generally involve single-dose evaluations in small samples of the young-old. Also, there is a lack of data regarding AED pharmacokinetics in the oldest-old, those individuals who may be at greatest risk for therapeutic failure and 
adverse reactions. A recent series of studies used stable-labeled isotopes of phenytoin, to determine the precise pharmacokinetics of this AED in elderly. 51

\section{Variability of AED levels in nursing homes}

Studies have shown that in compliant patients, the variability of AED concentrations over time is relatively small. One study showed that in institutionalized younger adults, the variability between serial phenytoin measurements over time was on the order of $10 \%$. Within the same study, compliant clinic patients experienced variability of approximately $20 \%{ }^{52}$ Approximately $5-10 \%$ of this variability may be due to inter-laboratory variability in measurement of drug concentrations, although laboratories not following rigid quality control standards may experience even larger amounts of variability. The remainder of noted variability could arise from day-to-day alterations in absorption, metabolism or differences in AED dose content. The variability for carbamazepine and valproate is on the order of $25 \%$, possibly due to their shorter half lives, which may increase sample time variability. ${ }^{53}$

A small study found that phenytoin levels may fluctuate in the NH elderly. ${ }^{54}$ This was confirmed in an analysis of serial phenytoin levels from NH patients across the US who had experienced no change in dose, formulation, or medication. ${ }^{55}$ Some patient's experienced a difference in concentration of two- to three-fold from the lowest to the highest level. Interestingly, some had very little fluctuation and were similar to that of the younger adults previously mentioned. ${ }^{55}$ Similar but less severe fluctuations were also observed for carbamazepine and valproic acid. These findings suggest that elderly frail NH residents may experience a greater variability in absorption of drugs. Factors that contribute to this variability in concentration must be identified and strategies should be developed in order to minimize this phenomenon. This phenomena also exists for valproate and carbamazepine, but to a lesser degree ${ }^{55}$ Attempting to adjust doses based on levels, unfortunately, only serves to increase the amplitude of the oscillations (personal observation. IEL). Thus, the best strategy at this time may be to obtain serial levels to identify persons who fluctuate and those who do not and consider using AEDs may not fluctuate. At this time, however, it is not known if the newer AEDs are less prone to variability. The causes of fluctuations in AED concentrations need to be identified by prospective studies that also identify characteristics which are associated with these fluctuations. These prospective studies are needed in order to determine if these changes in concentrations relate to clinically significant outcomes.

\section{Clinical trials of AEDs in the elderly}

All major AEDs have an FDA indication for use for the seizure types most likely to be encountered in the elderly. However, there is little data relating specifically to these drugs in the elderly, and those that are available have been limited to the community-dwelling elderly. One post-hoc VA cooperative study of carbamazepine and valproate found that elderly patients often had seizure control associated with lower AED levels than those seen in younger subjects. Notably, these elderly patient's also experienced side effects at lower levels compared with those scene in younger subjects 56 . 
A multicenter, double-blind, randomized comparison between lamotrigine and carbamazepine in newly diagnosed epileptic elderly patients (mean $=77$ years of age) in the United Kingdom showed that the main difference between the two groups was the rate of drop out due to adverse events, with lamotrigine incurring an $18 \%$ dropout rate compared to that of carbamazepine which incurred a $42 \%$ dropout rate. ${ }^{57}$ The VA Cooperative Study \#428, an 18-center, parallel, double-blind trial on the use of gabapentin, lamotrigine, and carbamazepine in patients $\ 60$ years of age found that drug efficacy did not differ, but the main finding favoring the two newer AEDs was better tolerability than carbamazepine. ${ }^{24}$

\section{Choosing AEDs for the elderly}

At the present time, there is little data regarding the clinical use of AEDs in the elderly. The paucity of information makes it very difficult to recommend specific AEDs with any confidence that outcomes will be optimal. A drug that is optimal for the $E H$ group may not be appropriate for the $E M M P$ or $F E$ groups due to the differences in pharmacokinetic or pharmacodynamic properties in these populations.

To date, phenytoin is still the most commonly used AED in both the community-dwelling and NH elderly within the US, although expert opinion may disagree with this practice. ${ }^{35}$ In the following sections, discussion is based first on the most commonly used AEDs for which there is more data, and is then followed by an alphabetical review of newer AEDs. Table 3 provides a summary of the properties of most AEDs.

\section{Phenytoin}

Phenytoin is effective for localization-related epilepsies, and thus has an efficacy profile appropriate for the elderly. Evidence for this can be gathered from a VA cooperative study which included elderly patients that found phenytoin to be as effective as carbamazepine, phenobarbital, and primidone, but that phenytoin and carbamazepine were better tolerated. ${ }^{58}$ Phenytoin has a narrow therapeutic range, is approximately $90 \%$ bound to serum albumin, and undergoes saturable metabolism, which has the effect of producing nonlinear changes in serum concentrations when the dose is changed or absorption is altered. Clinical studies in elderly patients have shown decreases in phenytoin binding to albumin and increases in free fraction. The binding of phenytoin to serum proteins correlates with the albumin concentration, which is typically low normal to subnormal in the elderly. One study compared the pharmacokinetics of phenytoin at steady state after oral administration in 34 elderly (60-79 years of age) persons, 32 middle-aged (40-59 years of age) persons, and 26 younger adult (20-39 years of age) persons with epilepsy. ${ }^{59}$ All subjects had normal albumin concentrations and liver function and received no other medications, including other AEDs known to alter hepatic metabolism. The maximum rate of metabolism $\left(\mathrm{V}_{\max }\right)$ declined with age, and significantly lower values were seen in the elderly group compared to the younger adults. ${ }^{59}$ Other earlier and smaller studies have also shown that phenytoin metabolism is reduced in the elderly. Therefore, smaller maintenance doses of phenytoin may be needed to attain desired unbound serum concentrations. Relatively small changes in dose $(<10 \%)$ are recommended when making dosing adjustments. Several NH studies revealed that residents were taking daily phenytoin lower than younger adults when 
measured by $\mathrm{mg} /$ day, but the dose expressed as $\mathrm{mg} / \mathrm{kg} /$ day were similar to those used in younger adults. ${ }^{60}$ This might suggest that metabolism may not decrease greatly with age. A study using stable labeled (non-radioactive) phenytoin to very precisely measure the phenytoin clearance found that advancing age was not as much of a factor as had been previously reported. ${ }^{51}$ In addition, a gender effect was found in this population as women required higher doses than men of PHT to achieve similar serum concentrations. ${ }^{60}$ Thus, in the elderly a starting daily dose of $3 \mathrm{mg} / \mathrm{kg}$ appears to be appropriate, rather than the 5 $\mathrm{mg} / \mathrm{kg}$ per day used in younger adults. ${ }^{61}$ This $3-\mathrm{mg} / \mathrm{kg}$ dose is only $160 \mathrm{mg} / \mathrm{day}$ for a $52 \mathrm{~kg}$ woman, or $200 \mathrm{mg} /$ day for a $66 \mathrm{~kg}$ man. Use of lower doses in the elderly may reflect agerelated changes to the therapeutic or toxic effects with advancing age more than a significant decline in hepatic functioning.

Due to the high protein binding of PHT, unbound PHT concentrations may be a better indicator of efficacy and toxicity than total concentrations. Measurement of unbound phenytoin concentrations is essential for elderly patients who have: (1) decreased serum albumin concentration; (2) total phenytoin concentrations that are near the upper boundary of the therapeutic range; (3) total concentrations that decline over time; (4) a low total concentration relative to the daily dose; or (5) total concentrations that do not correlate with clinical response. A range of $5 \mathrm{mg} / \mathrm{L}$ to $15 \mathrm{~m} / \mathrm{L}$ total may be more appropriate as a therapeutic range for the elderly. 61

Phenytoin has many drug-drug interactions and should be used cautiously in EMMP patients receiving other medications. Valproic acid, which is also highly protein bound, competes with phenytoin for albumin binding sites and inhibits phenytoin's metabolism.

Carbamazepine induces phenytoin metabolism and necessitates higher phenytoin doses. There is also some indication that SSRI antidepressants may inhibit the cytochrome 2C family of P450 enzymes responsible for metabolizing phenytoin. ${ }^{62}$ Fluoxetine and norfluoxetine are more potent inhibitors of this enzyme, followed by sertraline and paroxetine. The latter two SSRI antidepressants may prove to be a safer choice in the elderly. Coumadin also has a very complicated interaction with phenytoin and often doses of both need to be manipulated. ${ }^{61}$

Phenytoin has some effects on cognitive functioning, especially at higher phenytoin serum concentrations. ${ }^{63}$ However, it is not known if the elderly will be more sensitive to this problem. In addition, phenytoin may cause imbalance and ataxia. It is likely that $E M M P$ patients, especially those with CNS disorders, may be more sensitive to this medication. ${ }^{64}$ In a study involving elderly persons, among the various lifestyles, demographic, and health factors which contributed to an increased risk, phenytoin was the only drug which was associated with a significant increase in fractures. ${ }^{65}$ However, this study could not determine if this was due to falls from ataxia or seizures, or was an effect due to bone changes.

Phenytoin is also known to be a mild blocker of cardiac conduction, and should be used cautiously in persons with conduction defects, especially heart blocks. In spite of its limitations, phenytoin is the least expensive major AED. This, as well as its long record of use, may account for it presently being the most widely used AED. 


\section{Carbamazepine}

Carbamazepine is effective for localization-related epilepsies, and thus has an efficacy profile appropriate for the elderly. Evidence from two large VA Cooperative studies showed it to be as effective as phenytoin, phenobarbital, primidone, and valproate, but better tolerated than the latter three. ${ }^{58}, 66$ Two studies of new onset epilepsy in the communitydwelling elderly found it to be as effective as lamotrigine, but noted that it had a higher incidence of side effects. ${ }^{24}, 57$

The apparent clearance of carbamazepine has been reported to be $20 \%$ to $40 \%$ lower in the elderly as compared to adults. ${ }^{67}, 68$ A population analysis of patients from ambulatory neurology clinics at three medical centers also showed that the apparent oral clearance of carbamazepine was $25 \%$ lower in those patients who were greater than 70 years old. ${ }^{68}$ Decreases in clearance result in prolonged half-life elimination. These changes in carbamazepine pharmacokinetics indicate that lower and less frequent dosing in elderly patients may be appropriate. Lower doses of carbamazepine have been observed in older ( $>85$ years) elderly nursing home residents as compared to elderly in the younger age group (65-74 years); however, doses were similar after adjusting for a patients' weight. ${ }^{69}$ Observed carbamazepine concentrations in the Birnbaum study were lower or below the suggested therapeutic range used in treating younger adults.

Carbamazepine has some significant drug-drug interactions with medications that inhibit the cytochrome P450 enzyme, CYP3A4, responsible for carbamazepine metabolism. Among the inhibitors are erythromycin, fluoxetine, ketoconazole, propoxyphene (Darvon) and cimetidine (Tagamet). At least one food (grapefruit juice) has been identified to interact with carbamazepine causing increases in its serum concentrations. Elderly healthy patients will need to be cautioned about these interactions, and should be instructed to inform the physician whenever they are beginning a new medication, including any over-the-counter medications. Many other drug interactions do occur, so carbamazepine is one AED that will need to be used cautiously in EMMP patients receiving other medications.

Carbamazepine also induces the CYP3A4 system, reducing the effectiveness of other drugs. St. John's Wort, an herbal remedy used for depression, is a powerful inducer of CYP3A4 and may significantly lower the concentration of carbamazepine.

Carbamazepine has some effects on cognitive functioning, especially at higher levels. However, it is not known if the elderly will be more sensitive to this problem. In addition, carbamazepine may cause imbalance and ataxia. It is possible that $E M M P$ patients, especially those with CNS disorders, may be more sensitive to these effects. One of the major concerns with carbamazepine is its effect on sodium levels. ${ }^{70}$ Hyponatremia is a wellknown phenomenon seen with carbamazepine use, and may cause significant problems in younger adults, especially if there is polydypsia. The hyponatremia associated with carbamazepine is more pronounced as a person becomes older. ${ }^{71}$ This may become more problematic if a person is on a salt restriction diet or a diuretic. Because of the mild neutropenia associated with carbamazepine use in younger adults, the effects of this AED on hematopoetic parameters in the elderly will need to be studied. Carbamazepine is also 
known to affect cardiac rhythms, and should be used cautiously, if at all, in persons with rhythm disturbances.

One of the pharmacokinetic problems of carbamazepine is its short half-life, and its possible need to be taken multiple times a day. In the elderly, however, the half-life may be longer and slow-release formulations may overcome the need to dose multiple times each day and may overcome some of the side-effect problems associated with a rapid time to a high peak (short Tmax and high Cmax).

\section{Phenobarbital}

Phenobarbital is effective for localization-related epilepsies, and has an efficacy profile appropriate for the elderly. However, a VA Cooperative study demonstrated that phenobarbital and primidone are not as well tolerated when compared to carbamazepine or phenytoin. ${ }^{58}$ Thus, although phenobarbital is the least expensive of all AEDs, its side effects profile, which may worsen cognition and depression, make it an undesirable drug for the elderly, especially in the $\mathrm{NH}$ setting where declines in cognition are already present.

\section{Valproic Acid}

Only a few studies have compared the pharmacokinetics of valproic acid in young and old patients. ${ }^{72}, 73$ Total valproic acid clearance is similar in young and elderly individuals; however, unbound clearance is higher in the elderly.

Much like phenytoin, valproic acid is associated with reduced protein binding and unbound clearance in the elderly. As a result, the desired clinical response may be achieved with a lower dose. A nationwide elderly nursing home study showed that VPA dose and total VPA concentrations decrease within elderly age Groups. ${ }^{74}$ The apparent clearance of valproic acid in elderly nursing home residents has also been shown to be $27 \%$ lower in women, $41 \%$ greater with the co-administration of an inducer such as carbamazepine or phenytoin, and to be $25 \%$ greater when the syrup formulation was used. ${ }^{69}$ Because the serum elimination halflife may be prolonged, the dosing interval can be extended. If the albumin concentration has fallen or the patient's clinical response does not correlate with total drug concentration, measurement of the unbound drug should be considered. Because of its effects on mood stabilization, it may be especially appropriate for elderly patients with a dual diagnosis.

\section{Felbamate}

Felbamate is effective for localization-related epilepsies and appears to have a broader spectrum of effectiveness than some of the other AEDs. Elderly subjects had a lower mean clearance (31.2 vs $25.1 \mathrm{ml} / \mathrm{min}$; 90\% CI: 11.4 to $-0.9 ; \mathrm{p}=0.02$ ) than adults in a study involving 24 elderly healthy volunteers. ${ }^{75}$ Felbamate is primarily metabolized by the liver and is known to have a number of drug-drug interactions, both inhibitory and inductive, and therefore may not be a good choice for EMMP patients. 


\section{Gabapentin}

Gabapentin is effective for localization-related epilepsies, and has an efficacy profile appropriate for the elderly. Gabapentin is not metabolized by the liver, but rather renally excreted; therefore, there are no drug-drug interactions. ${ }^{76}$ Thus it may be especially useful in $E M M P$ patients. There is, however, a reduction of renal function that correlates with advancing age, so doses may need to be adjusted in both $E H$ and $E M M P$ patients. Levels must be monitored after initiation and doses adjusted accordingly. However, gabapentin does appear to have some sedative side effects, especially at higher levels, and the elderly may be more sensitive to this problem.

Gabapentin has a short half-life that requires it to be given multiple times a day. In the elderly, however, the half-life may be longer due to a reduction in renal elimination. Because gabapentin is effective in treating neuralgic pain, it may be additionally beneficial for someone suffering from both epilepsy and pain.

The VA Cooperative Study \#428 study compared carbamazepine with gabapentin and lamotrigine. Efficacies were similar but withdrawal related to side effects was highest for carbamazepine. ${ }^{24}$ This suggests that the newer AEDs may be better tolerated.

\section{Lamotrigine}

Lamotrigine is effective for localization-related epilepsies, and has an efficacy profile appropriate for the elderly. However, very few studies regarding lamotrigine and its effects on the elderly have been published. Lamotrigine is primarily metabolized by the liver using the glucuronidation pathway, which unlike the P450 system, is thought to be less affected by age. ${ }^{77}$ Data from a population pharmacokinetic study of 163 epilepsy patients, which only included 30 subjects greater than 65 years of age, 10 subjects between 70 and 76 years of age and no subjects from the old-old age group, showed that age did not effect lamotrigine apparent clearance. ${ }^{78}$ Based on a study of 150 elderly subjects, the drop out rate due to adverse events was lower with lamotrigine (18\%) than with carbamazepine (42\%). The difference was attributable to the finding that lamotrigine subjects had fewer rashes (lamotrigine 3\%, carbamazepine 19\%) and fewer complaints of somnolence (lamotrigine $12 \%$, carbamazepine 29\%). ${ }^{57}$ Clinicians may want to consider other factors when dosing elderly lamotrigine patients. Elderly community-dwelling epilepsy patients aged 59-92 years from the VA Cooperative \#428 Study showed that lamotrigine apparent clearance can be effected by blood urea nitrogen and serum creatinine ratio, weight and phenytoin use. ${ }^{79}$

Lamotrigine clearance is increased by approximately 2-3 times with co-administration of phenytoin and carbamazepine; whereas lamotrigine clearance decreases two-fold with coadministration of valproic acid. ${ }^{80}$ However, these drug interaction studies included very few elderly subjects. Therefore, the extent of the changes in clearance with administration of comedications in the elderly is not known, and caution may need to be observed in EMMP patients who are on other drugs. 


\section{Levetiracetam}

Levetiracetam has been approved as adjunctive therapy for partial-onset seizures in adults. Levetiracetam is extremely water soluble, which allows for rapid and complete absorption after oral administration. Levetiracetam is not metabolized by the liver, and thus is free of nonlinear elimination kinetics, auto induction kinetics, and drug-drug interactions. Lack of protein binding $(<10 \%)$ also avoids the problems of displacing highly protein-bound drugs and the monitoring of unbound concentrations. Also, lack of drug interactions would make it useful for treating elderly epilepsy patients, particularly those patients who have other illnesses and are taking other medications. ${ }^{81}$ Notably, the manufacturer reports a decrease of $38 \%$ in total body clearance and an increased half-life up to 2.5 hours longer in elderly subjects (age 61-88 years) who exhibited creatinine clearances ranging from 30-74 $\mathrm{ml} / \mathrm{min}$. However, doses do need to be adjusted depending on the renal function of the patient as measured by serum creatinine and levetiracetam concentrations. ${ }^{82}$

One prospective phase 4 study indicates a favorable efficacy profile in the elderly. ${ }^{83}$ Levetiracetam also appears to have a favorable safety profile. It was initially studied as a potential agent for treating cognitive disorders in the elderly, and thus a considerable amount of data regarding its tolerability in this age group is available. Analysis of 3,252 elderly persons involved in studies of levetiracetam for epilepsy and other conditions demonstrated that levetiracetam was well tolerated by the elderly. ${ }^{84}$

\section{Oxcarbazepine}

Oxcarbazepine is rapidly metabolized by first pass metabolism to 10-hydroxcarbazepine (10-OH-carbazepine or MHD); MHD is considered the active compound. MHD is further metabolized by glucuronidation and excreted by the kidneys. ${ }^{85}$ The most extensive elderly oxcarbazepine study involved low doses of oxcarbazepine given to 12 young and 12 elderly healthy male volunteers and 12 young and 12 elderly female volunteers. At low doses of oxcarbazepine (300-600 mg/day) a significantly higher maximum concentration, higher area under the curve parameters, and a lower elimination rate constant was observed in the elderly volunteers.

Oxcarbazepine can affect the cytochrome $\mathrm{P} 450$ system by inducing the metabolism of the CYP3A4 enzyme that is responsible for the metabolism of dihydropyridine calcium antagonists and many other substances using this pathway. ${ }^{87,88}$ However, oxcarbazepine appears to have a more powerful effect on sodium balance than carbamazepine and this effect has been shown to increase with age resulting in more pronounced hyponatremia in this age group. ${ }^{71}$

\section{Pregabalin}

Pregabalin is related to gabapentin but is more potent, with doses of only one-fifth those of gabapentin needed for therapeutic effect. Its absorption also appears to be more predictable because of the lower amounts transported across the intestinal system. Although it may prove to be a favorable AED for the elderly, its cost and lack of experimental and clinical data may limit its use. 


\section{Tiagabine}

Tiagabine is effective for localization-related epilepsies, has an efficacy profile appropriate for the elderly, and is primarily metabolized by the liver (CYP3A4). Co-medications that affect CYP3A4 substrates will also affect the metabolism of tiagabine, giving it a drug interaction profile similar to carbamazepine. A major feature of tiagabine is its potency; usually, effective doses are 20 to $60 \mathrm{mg}$ per day, and effective concentrations are 100 to 300 nanograms per milliliter, or as much as100-fold lower than other AEDs.

\section{Topiramate}

Topiramate is effective for localization-related epilepsies, and thus has an efficacy profile appropriate for the elderly. Topiramate is approximately $20 \%$ bound to serum proteins and is both metabolized by the liver and excreted unchanged in the urine. The enzymes involved in topiramate's metabolism have not been identified; however, the cytochrome P450 system may be involved. Topiramate clearance may decrease with age, causing higher than expected serum concentrations with doses that are used in younger adults. In addition, topiramate metabolism can be induced in the presence of inducing co-medications such as carbamazepine and phenytoin ${ }^{89}$. There is also some indication that topiramate can inhibit CYP2C19 activity. ${ }^{90}$ thus, levels will need to be monitored in order to ensure that the topiramate dose given does not result in higher than expected serum concentrations. Topiramate does have effects on cognitive functioning, especially at higher levels. However, it is not known if the elderly will be more sensitive to this problem.

\section{Zonisamide}

Zonisamide is effective for localization-related epilepsies. ${ }^{91}$ Protein binding is approximately $40 \%$ and its major elimination pathway is hepatic as a substrate of CYP 3A4. It may thus have interactions with other drugs using this pathway. In addition to the usual side effects of AEDS of somnolence and dizziness, zonisamide may be associated with weight loss. It has an association with the development of renal calculi in approximately $1-$ $2 \%$ of persons during chronic use. ${ }^{92}$

\section{Drug Interactions with Non-AEDs}

Co-medications are frequently used by patients in nursing homes receiving AEDs (Table 2). Thus, it is imperative to note that concomitant medications taken by elderly patients can alter the absorption, distribution, and metabolism of AEDs, thereby increasing the risk of toxicity or therapeutic failure.

Calcium-containing antacids and sucralfate reduce the absorption of phenytoin. ${ }^{93}, 94$ The absorption of phenytoin, carbamazepine, and valproate may be reduced significantly by oral antineoplastic drugs that damage gastrointestinal cells. ${ }^{95}, 96$ In addition, phenytoin concentrations may be lowered by intravenously administered antineoplastic agents. ${ }^{96}$ The use of folic acid for treatment of megaloblastic anemia may decrease serum concentrations of phenytoin and enteral feedings can also lower serum concentrations in patients receiving orally administered phenytoin. ${ }^{97}$ 
Many drugs displace AEDs from plasma proteins, an effect that is especially serious when the interacting drug also inhibits the metabolism of the displaced drug; this occurs when valproate interacts with phenytoin. Several drugs used on a short-term basis (including propoxyphene and erythromycin) or as a maintenance therapy (such as cimetidine, diltiazem, fluoxetine, and verapamil) significantly inhibit the metabolism of one or more AEDs that are metabolized by the P450 system. Certain agents can induce the P450 system or other enzymes, causing an increase in drug metabolism. The most commonly prescribed inducers of drug metabolism are phenytoin, phenobarbital, carbamazepine, and primidone. Ethanol, when used chronically, also induces drug metabolism. ${ }^{98}$

The interaction between antipsychotic drugs and AEDs is complex. Hepatic metabolism of certain antipsychotics such as haloperidol can be increased by carbamazepine, resulting in diminished psychotropic response. Antipsychotic medications, especially chlorpromazine, promazine, trifluoperazine, and perphenazine can reduce the threshold for seizures; and, the risk of seizure is directly proportional to the total number of psychotropic medications being taken, their doses, any abrupt increases in doses, and the presence of organized brain pathology. ${ }^{99}$ The epileptic patient taking antipsychotic drugs may need a higher dose of antiepileptic mediation to control seizures. In contrast, central nervous system depressants are likely to lower the maximum dose of AEDs that can be administered before toxic symptoms occur.

\section{Dosing}

Drug adherence (compliance) is a potential challenge in the elderly due to multiple medications, memory problems, and visual issues. In general, twice daily dosing is preferable. In long-term care facilities, drug adherence may be less of an issue than with community-dwelling elderly patients; however, reductions in staff and? time spent on the multiple administration of medicines may help to reduce errors and cost.

\section{Conclusions}

The eldrerly with epilepsy are a growing problem. Unfortunately little research has been done to determine the basic mechanisms underlying this disorder. Research has been hampered by a lack of appropriate models. Adding to the confusion is that there are many associated conditions which may predispose the brain to having seizures. Are the mechanisms leading to post-stroke epilepsy different from those predisposing to seizures in persons with Alzheimer's disease? Should different drugs be used for the various presentations? Elderly epileptic patients face issues that may alter the approach of AED treatments. Information obtained from studies of younger adults may at times be applicable to the elderly, but not in all instances. Community-dwelling elderly, relatively healthy except for epilepsy, may have similar patterns of response to AEDs. But AED levels may fluctuate significantly in the elderly nursing home population and dose changes based on a single level may exacerbate these already unstable levels. This has been shown for the older AEDs, but whether the newer or water soluble AEDs are better still needs to be demonstrated. Although age may influence hepatic clearance, earlier studies may have overestimated the degree of this effect; accordingly, the genetic make up of a patient's isoenzymes may play a 
much greater role than previously suspected. Of the newer AEDs, gabapentin, lamotrigine, and levetiracetam are the most widely researched and utilized. As drug patients expire, costs may lessen and lead to increasing use. However, much more research to develop evidence is needed in order to determine the best treatments for $E H, E M M P$, and $F E$ cohorts.

\section{References}

1. Administration on Aging. Washington, DC: 2005.

2. Hauser, W.; Hesdorffer, D. Epilepsy, Frequency, Causes and Consequences. New York, NY: Demos Publications; 1990.

3. Hauser WA, Annegers JF, Rocca WA. Mayo Clin Proc. 1996; 71:576-586. [PubMed: 8642887]

4. Epilepsy Foundation of America. Landover MD: 1999.

5. de la Court A, Breteler MM, Meinardi H, Hauser WA, Hofman A. Epilepsia. 1996; 37:141-147. [PubMed: 8635424]

6. Sillanpaa M, Kalviainen R, Klaukka T, Helenius H, Shinnar S. Epilepsy Res. 2006; 71:206-215. [PubMed: 16876984]

7. Fisher RS, Leppik I. Epilepsia. 2008; 49(Suppl 9):7-12. [PubMed: 19087112]

8. Fisher RS, van Emde Boas W, Blume W, Elger C, Genton P, Lee P, Engel J Jr. Epilepsia. 2005; 46:470-472. [PubMed: 15816939]

9. Bladin CF, Alexandrov AV, Bellavance A, Bornstein N, Chambers B, Cote R, Lebrun L, Pirisi A, Norris JW. Arch Neurol. 2000; 57:1617-1622. [PubMed: 11074794]

10. Silverman IE, Restrepo L, Mathews GC. Arch Neurol. 2002; 59:195-201. [PubMed: 11843689]

11. Leonard AS, JO M. Neuron. 2007; 55:677-678. [PubMed: 17785172]

12. Kelly KM, Nadon NL, Morrison JH, Thibault O, Barnes CA, EM B. Epilepsy Research. 2006; 68 S:S5-S20. [PubMed: 16386406]

13. Seyfried TN, Glaser GH, Yu RK, ST P. Adv Neurol. 1986; 44:115-133. [PubMed: 3518345]

14. Geinisman Y, de Toledo-Morrell L, Morrell F, RE H. Prog Neurobiol. 1995; 45:223-252. [PubMed: 7777673]

15. Du AT, Schuff N, Amend D, Laakso MP, Hsu YY, Jagust WJ, Yaffe K, Kramer JH, Reed B, Norman D, Chui HC, MW W. J Neurol Neurosurg Psych. 2001; 71:441-447.

16. Barnes CA. Int Rev Neurobilo. 2001; 45:339-354.

17. Shankar S, Teyler TJ. Robbins. Neurophysiol. 1998; 79:334-341.

18. de Toledo-Morrell L, Morrell F, S F. Behav Neurosci. 1984; 98:902-907. [PubMed: 6091704]

19. Leppik IE, Kelly KM, de Toledo-Morrell L, Patrylo PR, De Lorenzo RJ, Mathern GW, HS W. Epilepsy Research. 2006; 68S:S21-S37. [PubMed: 16384687]

20. Hartings JA, Williams AJ, FC T. Exp Neurol. 2003; 179:139-149. [PubMed: 12618120]

21. Karhunen H, Pitkanae A, Virtanen T, Gureviciene I, Pussinen R, Ylinen A, Sivenius J, Nissinen J, J J. Epilepsy Research. 2003; 54

22. DeLorenzo RJ, Sun DA, LS D. Proc Natl Acad Sci USA. 1998; 95:14482-14487. [PubMed: 9826726]

23. Palop JJ, Chin J, Roberson ED, Wang J, Thwin MT, Bien-ly N, Yoo J, Ho KO, Yu GO, Kreitzer A, Finkbeiner S, Noebels JL, L M. Neuron. 2007; 55:697-711. [PubMed: 17785178]

24. Rowan AJ, Ramsay RE, Collins JF, Pryor F, Boardman KD, Uthman BM, Spitz M, Frederick T, Towne A, Carter GS, Marks W, Felicetta J, Tomyanovich ML. Neurology. 2005; 64:1868-1873. [PubMed: 15955935]

25. Hauser WA. Epilepsia. 1992; 33(Suppl 4):S6-S14. [PubMed: 1425495]

26. Gupta SR, Naheedy MH, Elias D, Rubino FA. Stroke. 1988; 19:1477-1481. [PubMed: 3201504]

27. Holmes G. Clin Electroencephalogrl. 1980; 11:83-86.

28. Holmes GL. Clin Electroencephalogr. 1980; 11:83-86. [PubMed: 7389153]

29. Ensrud KE, Walczak TS, Blackwell TL, Ensrud ER, Barrett-Connor E, ES O. Group., O. F. i. M. M. S. R. Neurology. 2008; 71:723-730. [PubMed: 18765648] 
30. Ensrud KE, Walczak TS, Blackwell T, Ensrud ER BP, KL S. Neurology. 2004; 62:2051-1057. [PubMed: 15184613]

31. Leppik IE. Epilepsy Res. 2006; 68(Suppl 1):S1-S4. [PubMed: 16387475]

32. Leppik IE, Brodie MJ, Saetre ER, Rowan AJ, Ramsay RE, Macias F, Jacobs MP. Epilepsy Res. 2006; (Suppl 1):S71-S76. [PubMed: 16413171]

33. Moore, SA.; Teal, TW. Proceedings of the Drug Information Association Workshop Geriatric Drug Use: Clinical and Social Perspectives. Washington, DC: Pergamon Press; 1985. Adverse drug reaction surveillance in the geriatric population: a preliminary review.

34. Perucca E, Berlowitz D, Birnbaum A, Cloyd JC, Garrard J, Hanlon JT, Levy RH, Pugh MJ. Epilepsy Res. 2006; 68(Suppl 1):S49-S63. [PubMed: 16207524]

35. Pugh M, Cramer J, Knoefel J, Charbonneau A, Mandell A, Kazis L, Berlowitz D. J Am Geriatr Soc. 2003; 52:417-422. [PubMed: 14962158]

36. Kemper P, Murtaugh CM. N Engl J Med. 1991; 324:595-600. [PubMed: 1992320]

37. Hetzel, L.; Smith, A. The 65 years and over population: 2000. Census 2000 Brief; Census Bureau, C2KBR/01-10. Washington, D.C: 2001.

38. Garrard J, Harms S, Hardie N, Eberly LE, Nitz N, Bland P, Gross CR, Leppik IE. Ann Neurol. 2003; 54:75-85. [PubMed: 12838522]

39. Galimberti CA, Magri F, Magnani B, Arbasino C, Cravello L, Marchioni E, Tartara A. Epilepsy Res. 2006; 68:1-8. [PubMed: 16330188]

40. Lackner TE, Cloyd JC, Thomas LW, Leppik IE. Epilepsia. 1998; 39:1083-1087. [PubMed: 9776329]

41. Wallace S, Verbeeck R. Clin Pharmacokinet. 1987; 12:91-97.

42. Greenblatt DJ. J Am Geriatr Soc. 1979; 27:20-22. [PubMed: 759470]

43. Verbeeck RK, Cardinal JA, Wallace SM. Eur J Clin Pharmacol. 1984; 27:91-97. [PubMed: 6489431]

44. Wynne HA, Cope LH, Mutch E, Rawlins MD, Woodhouse KW, James OF. Hepatology. 1989; 9:297-301. [PubMed: 2643548]

45. Tiula E, Neuvonen PJ. N Engl J Med. 1982; 307:1148. [PubMed: 7121533]

46. Cusack BJ. J Clin Pharmacol. 1988; 28:571-576. [PubMed: 3047183]

47. Dawling S, Crome P. Clin Pharmacokinet. 1989; 17:236-263. [PubMed: 2686883]

48. Ahn JE, Cloyd JC, Brundage RC, Marino SE, Conway JM, Ramsay RE, White JR, Musib LC, Rarick JO, Birnbaum AK, Leppik IE. Neurology. 2008; 71:38-43. [PubMed: 18591503]

49. Rowe JW, Andres R, Tobin JD, Norris AH, Shock NW. J Gerontol. 1976; 31:155-163. [PubMed: 1249404]

50. Fehrman-Ekholm I, Skeppholm L. Scand J Urol Nephrol. 2004; 38:73-77. [PubMed: 15204431]

51. Ahn J, Cloyd J, Brundage R, Marino S, Conway J, Ramsay R, White J, Musib L, Rarick J, Birnbaum A, Leppik I. Neurology. 2008; 71:38-43. [PubMed: 18591503]

52. Leppik IE, Cloyd JD, Sawchuk RJ, Pepin SM. Ther Drug Mon. 1979; 1:475-483.

53. Graves NM, Holmes GB, Leppik IE. Epilepsy Res Suppl. 1988; 1:91-99. [PubMed: 3072193]

54. Mooradian AD, Hernandez L, Tamai IC, Marshall C. Arch Intern Med. 1989; 149:890-892. [PubMed: 2705838]

55. Birnbaum A, Hardie NA, Leppik IE, Conway JM, Bowers SE, Lackner T, Graves NM. Neurology. 2003; 60:555-559. [PubMed: 12601091]

56. Ramsay R, Rowan A, Slater J, Collins J, Nemire R, Oritz W. Epilepsia. 1994; 35:91.

57. Brodie MJ, Overstall PW, Giorgi L. Epilepsy Res. 1999; 37:81-87. [PubMed: 10515178]

58. Mattson RH, Cramer JA, Collins JF, Smith DB, Delgado-Escueta AV, Browne TR, Williamson PD, Treiman DM, McNamara JO, McCutchen CB, et al. N Engl J Med. 1985; 313:145-151. [PubMed: 3925335]

59. Bauer LA, Blouin RA. Clin Pharmacol Ther. 1982; 31:301-304. [PubMed: 7060313]

60. Birnbaum AK, Hardie NA, Conway JM, Bowers SE, Lackner TE, Graves NM, Leppik IE. Am J Geriatr Pharmacother. 2003; 1:90-95. [PubMed: 15555471] 
61. Leppik, IE. Contemporary Diagnosis and Management of the Patient with Epilepsy $6^{\text {th }}$ Ed. Newton. PA: Handbooks in Healthcare; 2006.

62. Nelson MH, Birnbaum AK, Remmel RP. Epilepsy Res. 2001; 44:71-82. [PubMed: 11255075]

63. Thompson P, Huppert FA, Trimble M. Br J Clin Psychol. 1981; 20:155-162. [PubMed: 7284649]

64. Bourdet SV, Gidal BE, Alldredge BK. J Am Pharm Assoc (Wash). 2001; 41:421-436. [PubMed: 11372907]

65. Bohannon AD, Hanlon JT, Landerman R, Gold DT. Am J Epidemiol. 1999; 149:1002-1009. [PubMed: 10355375]

66. Mattson RH, Cramer JA, Collins JF. N Engl J Med. 1992; 327:765-771. [PubMed: 1298221]

67. Cloyd JC, Lackner TE, Leppik IE. Arch Fam Med. 1994; 3:589-598. [PubMed: 7921294]

68. Graves NM, Brundage RC, Wen Y, Cascino G, So E, Ahman P, Rarick J, Krause S, Leppik IE. Pharmacotherapy. 1998; 18:273-281. [PubMed: 9545146]

69. Birnbaum AK, Conway JM, Hardie NA, Lackner TE, Bowers SE, IE L. Epilepsy Research. 2007; 77:31-35. [PubMed: 17890057]

70. Henry DA, Lawson DH, Reavey P, Renfrew S. Br Med J. 1977; 1:83-84. [PubMed: 832021]

71. Dong X, Leppik IE, White J, Rarick J. Neurology. 2005; 65:1976-1978. [PubMed: 16380624]

72. Bryson SM, Verma N, Scott PJ, Rubin PC. Br J Clin Pharmacol. 1983; 16:104-105. [PubMed: 6411107]

73. Perucca E, Grimaldi R, Gatti G, Pirracchio S, Crema F, Frigo GM. Br J Clin Pharmacol. 1984; 17:665-669. [PubMed: 6430313]

74. Birnbaum AK, Hardie NA, Conway JM, Bowers SE, Lackner TE, Graves NM, Leppik IE. Epilepsy Res. 2004; 62:157-162. [PubMed: 15579303]

75. Richens A, Banfield CR, Salfi M, Nomeir A, Lin CC, Jensen P, Affrime MB, Glue P. Br J Clin Pharmacol. 1997; 44:129-134. [PubMed: 9278196]

76. Richens, A. Clinical pharmacokinetics of gabapentin. London, England: Royal Society of Medicine Services; 1993.

77. Peck AW. Epilepsia. 1991; 32(Suppl 2):S9-S12. [PubMed: 1773780]

78. Hussein Z, Posner J. Br J Clin Pharmacol. 1997; 43:457-465. [PubMed: 9159559]

79. Rowan A, Ramsay R, Collins J, et al. Neurology. 2005; 64:1868-1873. [PubMed: 15955935]

80. Yuen AW, Land G, Weatherley BC, Peck AW. Br J Clin Pharmacol. 1992; 33:511-513. [PubMed: 1524964]

81. Patsalos PN, Sander JW. Drug Saf. 1994; 11:37-67. [PubMed: 7917080]

82. French J. Epilepsia. 2001; 42(Suppl 4):40-43. [PubMed: 11564125]

83. Morrell MJ, Leppik I, French J, Ferrendelli J, Han J, Magnus L. Epilepsy Res. 2003; 54:153-161. [PubMed: 12837566]

84. Cramer JA, Leppik IE, Rue KD, Edrich P, Kramer G. Epilepsy Res. 2003; 56:135-145. [PubMed: 14642998]

85. Faigle JW, M G. Behav Neurol. 1990; 3:21-30. [PubMed: 24487082]

86. van Heiningen PN, Eve MD, Oosterhuis B, Jonkman JH, de Bruin H, Hulsman JA, Richens A, Jensen PK. Clin Pharmacol Ther. 1991; 50:410-419. [PubMed: 1914377]

87. Klosterskov Jensen P, Saano V, Haring P, Svenstrup B, Menge GP. Epilepsia. 1992; 33:1149-1152. [PubMed: 1464278]

88. Zaccara G, Gangemi PF, Bendoni L, Menge GP, Schwabe S, Monza GC. Ther Drug Monit. 1993; 15:39-42. [PubMed: 8451779]

89. Sachdeo RC, Sachdeo SK, Walker SA, Kramer LD, Nayak RK, Doose DR. Epilepsia. 1996; 37:774-780. [PubMed: 8764818]

90. Levy R, Bishop F, Streeter A, Trager W, Kunze K, Thummel T, Mather G. Epilepsia. 1995; 36

91. Leppik IE, Willmore LJ, Homan RW, From G, Oommen KJ, Penry JK, Sackellares JC, Smith DB, Lesser RP, Wallace JD, rudeau JL, Lamoreaux LK, M S. Epilepsy Research. 1993; 14:165-173. [PubMed: 8453952]

92. Wroe O. Curr Med Res Opin. 2007; 23:1765-1773. [PubMed: 17594758]

93. Nation RL, Evans AM, Milne RW. Clin Pharmacokinet. 1990; 18:131-150. [PubMed: 2180613] 
94. Nation RL, Evans AM, Milne RW. Clin Pharmacokinet. 1990; 18:37-60. [PubMed: 2178849]

95. Bollini P, Riva R, Albani F, Ida N, Cacciari L, Bollini C, Baruzzi A. Epilepsia. 1983; 24:75-78. [PubMed: 6822234]

96. Neef C, de Voogd-van der Straaten I. Clin Pharmacol Ther. 1988; 43:372-375. [PubMed: 3128415]

97. Haley CJ, Nelson J. Dicp - Ann Pharmacother. 1989; 23:796-798.

98. Sandor P, Sellers EM, Dumbrell M, Khouw V. Clin Pharmacol Ther. 1981; 30:390-397. [PubMed: 7273603]

99. Cold JA, Wells BG, Froemming JH. Dicp - Ann Pharmacother. 1990; 24:601-606.

100. Birnbaum A, Hardie N, Leppik I, et al. Neurology. 2003; 60:555-559. [PubMed: 12601091] 


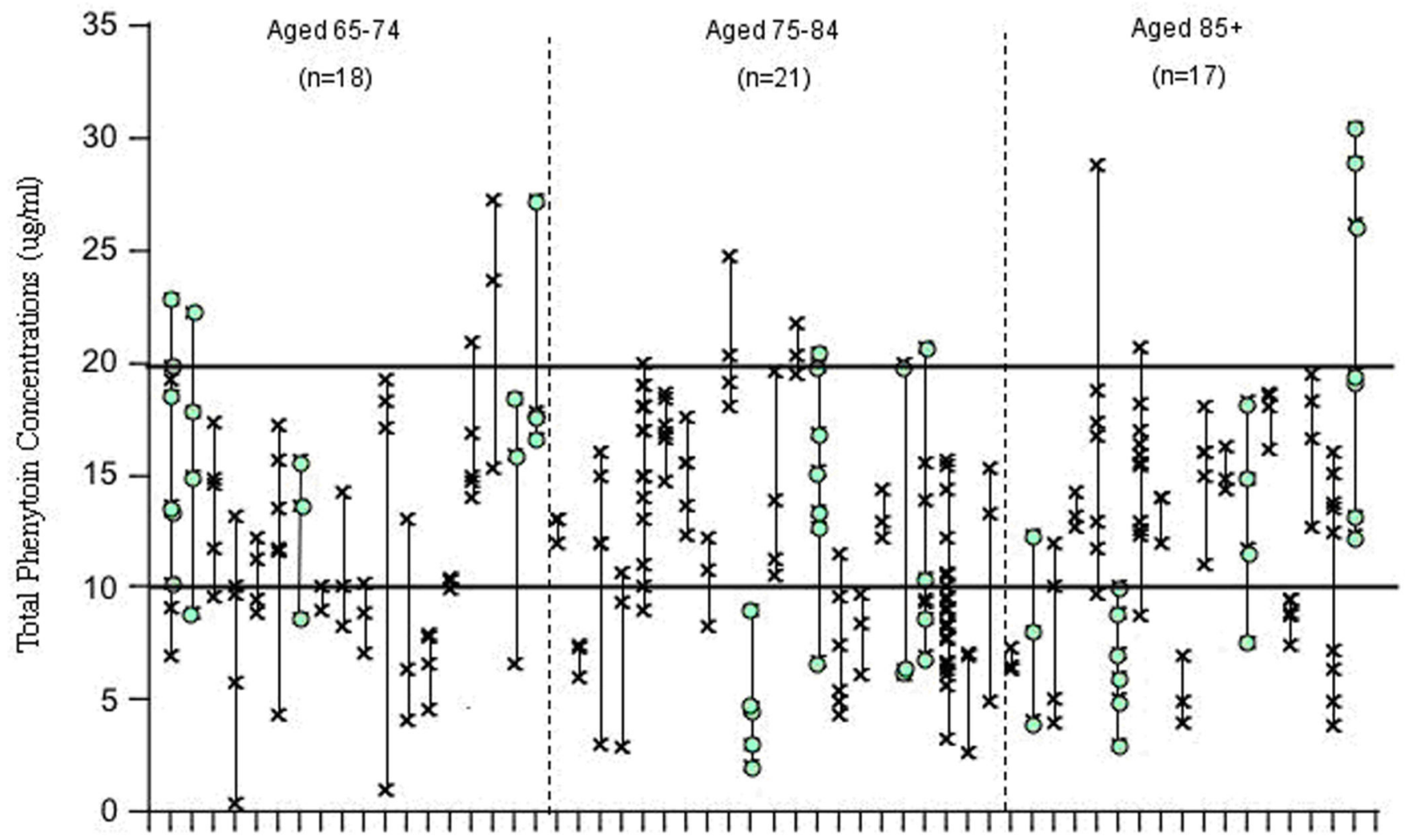

Individual Elderly Residents Categorized by Age Group at Emrollment

Figure 1. Variablity of phenytoin concentrations in elderly nursing home residents

The subjects were included in the figure if: they had no change in phenytoin dose over all of the measurements, they were on no medications which would alter phenytoin clearance and had standing orders for routine serial phenytoin measurements. Each vertical column incorporates the concentrations from a single subject. Subjects are arranged in order of ascending age. Levels in each subject varied randomly over time. Note that although many subjects had large variations over time, some had little fluctuation. Data re4garding medical condition of subjects was not available. This problem is now being investigated by a prospective study to determine the causes and consequences of fluctuating levels. Used by permission from authors and publisher. ${ }^{100}$ 


\section{Table 1}

Categorization of elderly with epilepsy

\begin{tabular}{ccc}
\hline $\begin{array}{c}\text { Young- Old Healthy } \\
\text { EH }\end{array}$ & $\begin{array}{c}\text { Middle- Old Healthy } \\
\text { EH }\end{array}$ & $\begin{array}{c}\text { Old-Old Healthy } \\
\text { EH }\end{array}$ \\
\hline Young- Old Multiple \\
Medical Problems \\
EMMP & Middle Old Multiple & Old-Old Old Multiple \\
& Medical Problems & Medical Problems \\
EMMP & EMMP \\
Young- Old Frail & Middle Old Frail & Old-Old Frail \\
FE & FE & FE \\
\hline 31 & &
\end{tabular}

Modified from $^{31}$. 


\section{Table 2}

Frequency of use of co-medications with potential pharmacokinetic or pharmacodynamic interactions with antiepileptic drugs in 4.291 residents of nursing

\begin{tabular}{ll}
\hline Drug Category & \% use with AEDs \\
Antidepressants & 18.9 \\
Antipsychotics & 12.7 \\
Benzodiazepams & 22.4 \\
Thyroid supplements & 14.0 \\
Antacids & 8.0 \\
Calcium Channel Blockers & 6.9 \\
Warfarin & 5.9 \\
Cimetidine & 2.5 \\
\hline
\end{tabular}

From Lackner et. al., 1998 .

From Lackner et. al. 1998. 
Table 3

AED Pharmacokinetics in the Elderly

\begin{tabular}{|c|c|c|c|}
\hline Drug & $\begin{array}{l}\text { Protein } \\
\text { binding }\end{array}$ & Elimination & Comments \\
\hline Carbamazepine & $75-85 \%$ & $\begin{array}{l}\text { hepatic } \\
\text { CYP 3A4/5 }\end{array}$ & $\begin{array}{l}\text { Protein binding decreased with age } \\
\text { Levels increased by erythromycin, } \\
\text { prophoxyphene and grapefruit juice } \\
\text { Decreases levels of calcium channel } \\
\text { blockers (dilitiazem, verapamil), } \\
\text { Decreases effect of warfarin, } \\
\text { Decreases tricyclic antidepressant levels }\end{array}$ \\
\hline Felbamate & $<10 \%$ & hepatic & \\
\hline Gabapentin & $<10 \%$ & renal & $\begin{array}{l}\text { Elimination correlates with creatinine } \\
\text { clearance } \\
\text { No drug interactions }\end{array}$ \\
\hline Lamotrigine & $55 \%$ & $\begin{array}{l}\text { hepatic- } \\
\text { glucuronide } \\
\text { conjugation }\end{array}$ & $\begin{array}{l}\text { Levels decreased by inducing agents- } \\
\text { carbamazepine, phenytoin, some hormones } \\
\text { and others yet to be determined. } \\
\text { Levels increased by vaproate }\end{array}$ \\
\hline Levetiracetam & $<10 \%$ & renal & $\begin{array}{l}\text { Very water solun]ble, IV formulation } \\
\text { available } \\
\text { No drug interactions }\end{array}$ \\
\hline Oxcarbazepine & $40 \%$ & hepatic & Causes hyponatremia \\
\hline Phenobarbital & $50 \%$ & $\begin{array}{l}\text { Hepatic } \\
\text { renal }\end{array}$ & Induces metabolism of many drugs \\
\hline Phenytoin & $80-93 \%$ & $\begin{array}{l}\text { hepatic } \\
\text { CYP 2C9 } \\
\text { CYP 2C19 }\end{array}$ & $\begin{array}{l}\text { Protein binding decreased with reduced } \\
\text { serum albumin and renal failure. } \\
\text { Decreases levels of calcium channel blockers } \\
\text { (dilitiazem, verapamil), } \\
\text { Complicated interaction with warfrin } \\
\text { Decreases tricyclic antidepressant levels } \\
\text { Interacts with diabetes and arthritis } \\
\text { medications } \\
\text { Decreases effectiveness of cancer } \\
\text { chemotherapy }\end{array}$ \\
\hline Topiramate & $9-17 \%$ & $\begin{array}{l}\text { hepatic and } \\
\text { renal }\end{array}$ & $\begin{array}{l}\text { Inhibits CYP 2C19 and increase serum } \\
\text { Phenytoin and other drug levels } \\
\text { Induces CYP-3A4 isoenzymes }\end{array}$ \\
\hline Valproic acid & $87-95 \%$ & $\begin{array}{l}\text { hepatic } \\
\text { multiple } \\
\text { pathways }\end{array}$ & $\begin{array}{l}\text { Protein binding decreased in elderly. } \\
\text { Inhibits glucuronidation and may increse } \\
\text { levels of lamotirigine and other drugs } \\
\text { Decreases platelet function }\end{array}$ \\
\hline Zonisamide & $40 \%$ & $\begin{array}{l}\text { Hepatic } \\
\text { CYP 3A4 }\end{array}$ & Weight loss and nephrolithiasis are issues \\
\hline
\end{tabular}

